\title{
The risk sharing of client request error terms in DB mode
}

\author{
Shan Zhou ${ }^{\text {a }}$, Saoyan Wu ${ }^{\text {b }}$ \\ School of Tianjin University of Technology, Tianjin, China \\ azhoushanezs@126.com, bshaoyanwu@126.com
}

\begin{abstract}
The DB general contractor needs to be done according to client requirement design of part or all of the work, the developer in the preliminary design stage tender, general mainly provide relevant conceptual, basic requirements of the project, which unavoidably exist errors and biases. As for the request is not clear, the design information is not complete, time nervous cause design accuracy is not enough. If the employer in the bidding and construction drawing design stage, while the developer provides a relatively detailed design documents, but there still may be inevitable errors. The developer because of subjective or objective error causes of client request, may cause delays due to design changes and changes to problems such as the price dispute, engineering change agreement is not clear lead to change the understanding of both parties after the occurrence of deviation, change the controversy, the key to solve the dispute of engineering change is to clarify what kind of work does fall within the scope of engineering change adjustment.
\end{abstract}

Keywords: Client requirement; B terms; Engineering change.

\section{Introduction}

Project contract is the client for a specific function of the building and sign service contract with the contractor, the realization of the rights of the contract depends on the needs of the state of nature. Because of people's bounded rationality, information incompleteness and uncertainty of transaction, and makes the practical engineering project is influenced by many factors lead to contract cost or the high cost of execution, inevitable existence of incomplete contract of [1]. But there is no too much choice [2], contracting parties of incomplete contract is inevitable, only by the terms of the contract management project cannot fully deal with various risks arising from the contract. Considering the DB general contracting model development is not mature, and domestic market share is small, and the strength of the domestic design and construction general contractor has yet to reach the requirements of the international level. In order to guarantee the implementation of the contract efficiency, on the basis of construction general contracting common characteristics, nine ministries jointly awarded the twelfth 12 version of the standard design and construction general contracting tender document "(hereinafter referred to as the DB standard file), the initial design in advance in the contract under the terms of the selective flexibility of different state changes in response to project risk, namely it increases the terms of A and B that can be chose by yourself. Its purpose is to sign a contract both sides are fair to sending the complete contract, at the same time advocate to choose the thought of $\mathrm{A}$ and B clause freely [3].

DB standard file of general conditions mainly including core terms, guarantee terms and other accessories, including core terms is the key of the preparation of contract [4]. In terms of core involved in terms of $\mathrm{A}$ and $\mathrm{B}$ can choose the project with client requirements errors, unpredictable, material conditions, materials and engineering equipment, peon, temporarily valuation, price fluctuation caused by the adjustment, after the completion of acceptance, and the employer asks as the most original and generalization of the project, the most can reflect the core terms of client needs, and put forward to build A factory is not simple, or only use several simple drawing can describe clearly, but A comprehensive and detailed project requirements. Client required by the accurate detail has a crucial effect on the smooth implementation of project. Client requirements in terms of $\mathrm{A}$ and $\mathrm{B}$, is the main role in the whole standard in the design and construction contract conditions can embody the maximum flexibility as far as possible, at the same time have a certain standard [5]. 


\section{The content of the article}

\subsection{The both sides of the risk allocation matrix in $A$ and $B$ terms}

The terms of $\mathrm{A}$ and $\mathrm{B}$ in the DB mode, according to the terms of the selected when signing A contract, the extent of the risk of contracting parties to assume different column matrix of risk sharing as shown in table 1 . Based on the completion of attribution, imputation study, establish the attribution and goes on to the relationship between imputations.

Table 1 the requirements of the client risk allocation matrix

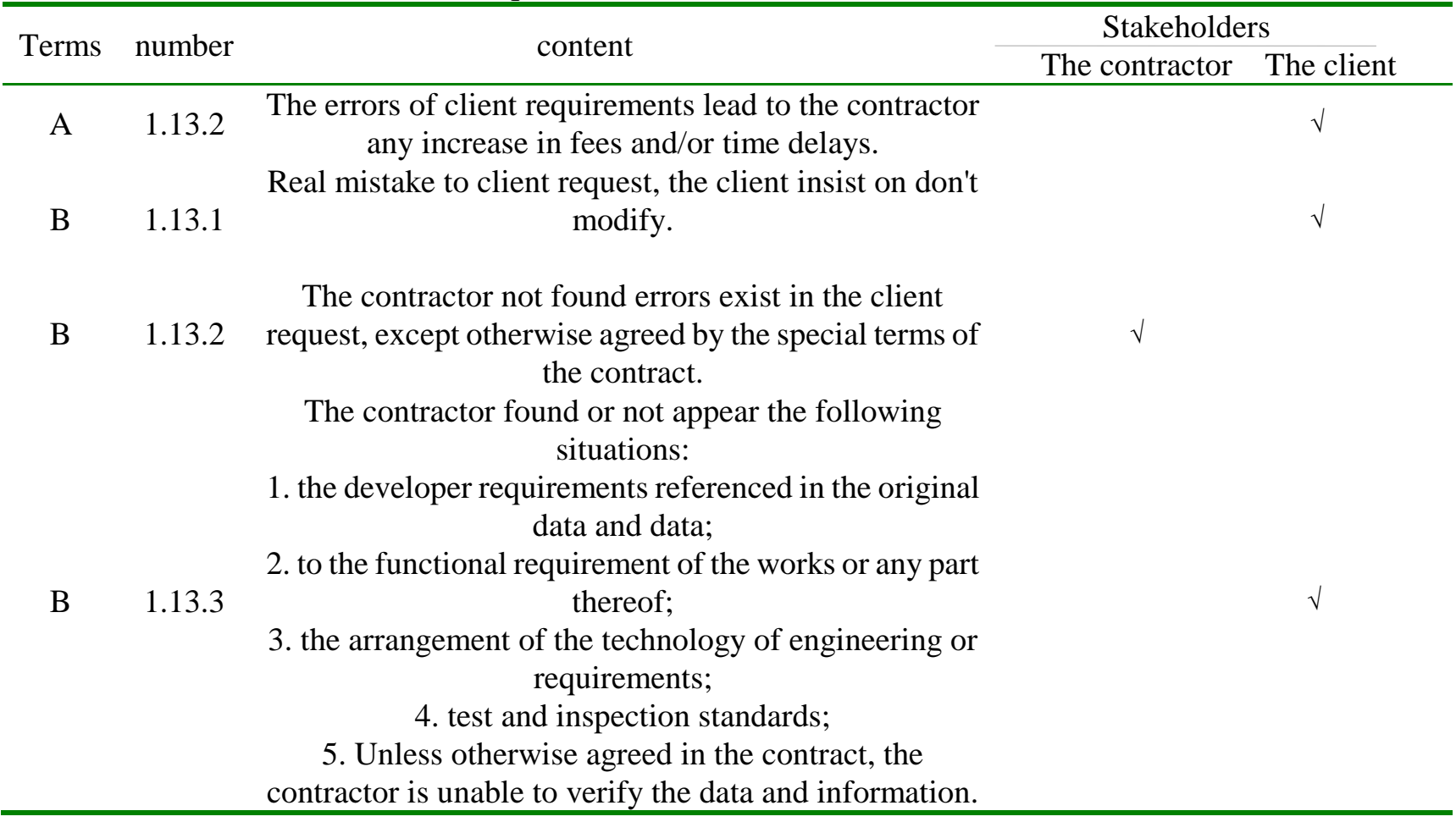

A clause in the principle of responsibility [6], rights, equality, no matter whether the contractor found errors, caused by the errors in the client request to rise in the cost of the contractor or the construction period delay, etc., the developer should make reasonable compensation to the contractor, the contractor for social morality should also try to implement the functions of review. The developer will all the work of construction project contract awarding, usually choose B clause. B under the terms of price relative height locking, leave some less open contract, unless otherwise agreed by the table 1 five situation and refused to change the situation, the contractor has not found errors existing in the client requirements, the contractor will bear the loss caused by the behavior; And B unless otherwise agreed under the terms of the five, based on the principle of fair justice, no matter whether the contractor found errors, risk shall be borne by the developer. However, in the concrete implementation process, some terms describe vague content, it is difficult to define whether it belongs to change, so the two sides should clear risk of contractors, in order to avoid dispute and related issue in the future.

\subsection{Get rid of fuzzy research in the terms of $B$}

The terms of the contract with the choice of contracting parties form a specific investment and project hold up relationship, the responsibility of the different choice of different terms. In the process of concluding the contract, both parties according to the expectations of their game and reach an agreement and interests, but given the existence of asymmetric information and uncertain factors, led to the contracting contract signed by both parties is incomplete, the contracting parties tend to use a loophole in the agreement is not to seek the maximization of self-interest, make both parties have to consume more time cost and resources cost to put forward contract conditions advantageous to their side, reduces the efficiency of the project. Based on this, this article on the basis of the initial contract, combined with the actual situation of this project is to identify the client request in B clauses in the disputed matters by agreement is not clear. 


\subsection{The identification of critical control points in the terms of $B$}

About the developer in a clause, the employer should be responsible for errors in the range of more clear. B terms and comparison, the developer will be a part of the client request error risk transfer to the contractor, the contractor risk increases, at the same time, the developer is in line with the principle of "high-risk high-yield" give high fixed price contract by the contractor. But contracting parties' understanding of some risks, the contractor when encountered in the construction process of adverse circumstances, apply for compensation, the employer often rejected for various reasons. In this case issued contract both sides should focus on risk control of the key points, clear risk limits on both sides.

Analysis of critical control points, found that the "client requirements referenced in the raw data and information" and "unless otherwise agreed in the contract, the contractor can't verify the data and information" in both cases the seemingly similar data and information, actually otherwise. The data provided by the contractor in accordance with the client and the information design and construction, due to some subjective or objective reasons will lead to the change of the construction scheme, but not all of the data and information mistake belong to should undertake the responsibility of the contractor. Analysis the cause of change, and reasonable allocation of risks, to avoid contracting of debate on both sides. Test and inspection standards belong to another kind of A and B terms and conditions of the situation, not be discussed in this paper. Engineering technology arrangement or requirements description is relatively simple, obvious boundary between both the responsibilities and also not be described in detail in this paper. The employer in the tender, only provide basic data and asked to describe the function of the works or any part thereof are short, and the understanding of the different people treat the same description may be different, in the process of construction project is affected by natural conditions and human instruction, prone to understand error, the contractor in the implementation of engineering change the phenomenon of the original project plan is very common.

Contract for engineering change for the initial project belongs to the accidental events, the original work plan, work procedure and construction scheme will affect, and engineering change is not a separate process, must maintain unity and oneness with the initial project contract. B terms for risk sharing principle is equipped with the original data and information as well as the use of the works or any part of its function mechanism of rigid procedures, different treatment method of risk allocation scheme and the contracting party obligations each are not identical, but in the practical engineering for engineering change the scope of the provisions of the clause is not clear. The above dispute and the root of the problem is that the engineering change prior to the contracting part is only a blur.

\section{The original data and data analysis in the terms of $B$}

Client mainly provides and is responsible for the data including the construction site and adjacent to the area of water supply, water drainage, power supply, gas supply, heating, communications, radio and television, such as underground pipeline data [7], of the underground engineering related information [8], positioning steel benchmark, baseline and benchmark level [9], the developer of the examination and approval, the approval and record filing materials. These data to determine the initial state of the project has the vital role.

\subsection{The original data and information integration}

The developer in the tender stage will usually provide basic data and field obstacle information of the project, in addition to solve the bidder upfront cost a lot of manpower material resources to survey the scene, however, is not necessarily outside the dilemma will be agreed at the same time the developer responsible for the accuracy of the above information and authenticity. The contractor shall be provided in the developer after the original data and information in a timely manner to the construction site for reconnaissance survey, but it is often difficult to find all the questions within the deadline. The contractor shall fully consider the risk of this section in the process of bidding for the influence degree of the design and construction contract, at the same time, the two sides during the 
period of the contract the contracting clear this part of the risk and bear the principle, considering to reduce both sides dispute, achieve win-win situation.

\subsection{Data and the data accuracy and completeness of the contractors the interests of both sides}

Contractor according to the bidding phase information and data of the client to provide the initial construction plan of the project, the accuracy and completeness of data and information with the project later the situation whether there is a causal relationship. The relative data in underground engineering as an example, first of all, the developer should provide accurate underground engineering material, the contractor only verify the obligation that such information is complete, and no obligation as a geologist or geotechnical engineer to verify the accuracy of the data; Second, the developer should be owned, may affect the judgment of underground engineering condition of all the original information provided to the contractor. No obligation for the contractor to the information provided in the developer to find other additional data, there is reason to believe that the developer of the information provided is complete and accurate.

By urban underground engineering in the construction process of location decision of almost impossible to completely isolated from the surrounding environment, tend to be in line with, building density, big flow and flow under the environment of the construction, and because the concealment of the underground engineering, geological structure, structure, fracture characteristics and composition of soil and groundwater, underground cavity and other adverse geological body before is excavated, difficult to precisely determine, under the condition of the objective environment, determines the high risk in construction of new construction, in the event of accident, will cause huge economic losses and serious social influence [10]. Real life of the original data and information provided about the developer is inaccurate or incomplete case is more, such as excavators in one venue construction, construction site due to incomplete, inaccurate data of unforeseen circumstances, such as part of the gas pipeline damage and these conditions is the contractor based on previous construction experience not to foresee, once happen often cause huge economic losses, shall be borne by the employer.

\section{The functions of the works or any part of its analysis in the terms of $B$}

The employer as much as possible in addition to provide the raw data and data clearly and concisely, in respect of the work can quantitatively evaluate the employer requirements also make clear a regulation function, purpose, and stipulate the scope of deviation, and function of the details. The functional requirement of the project refers to the substance can meet the design using the basic requirement of function and achieve the desired effect.

\subsection{The concept of functional requirements and defined}

The functional requirement of the project embodies the purpose of the project activity, the contractor fully understand the functional requirements is the key project smoothly. The implementation of the bidding law "on the" winning a tender with reasonable low price, completely changed the whole construction project price formation mechanism, be determined by the administrative department in accordance with the quotas, shift to the competition mechanism formed by the market. Market competition mechanism representation is price competition, the essence of which is cost competition, however, the cost of high and low will directly affect the function of the implementation. While the cost control theory has formed a systematic theory and the mature tools, but in actual engineering, there are still many shortcomings and the insufficiency in cost control, for example, the scale of the project estimation does not reach the designated position, the determination of scale is the key of cost control [11], so the project size same as a basic content of the engineering requirements. The contents of the functional requirement analysis is shown in figure 1. 


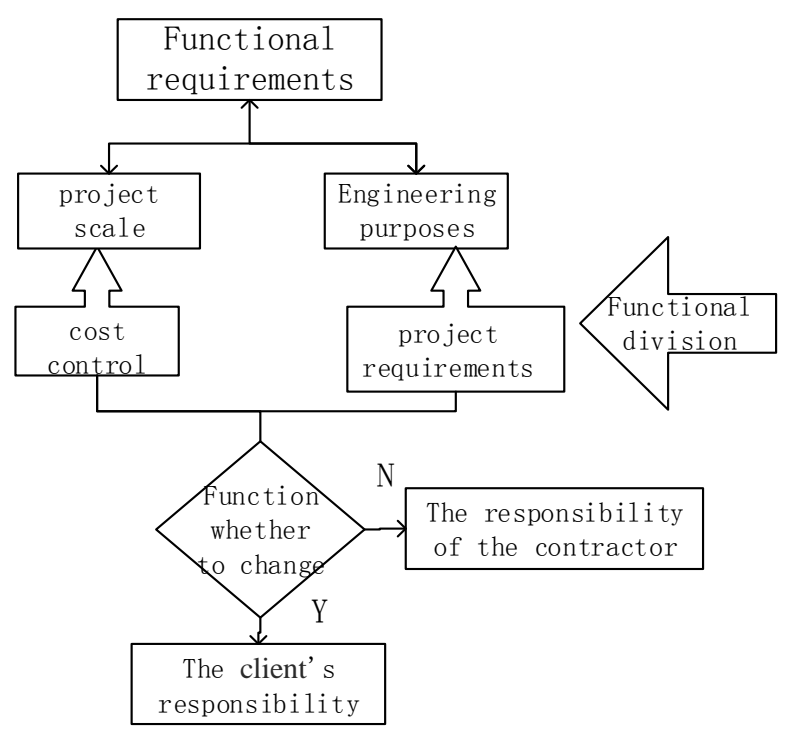

Figure 1 The content of the functional requirements

\subsection{The controversy of Functional requirements change}

Negligence by the developer and the contractor's reason, lead to the contract did not perform properly, thus brought loss to the contractor, the contractor has the right to require the employer to compensate this part delays and costs. Due to the developer in the position in the whole project management and other reasons, the contractor is not always smooth successfully gain compensation, when the event occurs, the employer usually on the grounds that the functional requirement has not changed, refused to compensate. At this time how to define the functional requirements whether to change to become the key factor to solve the problem of the [12], this paper from two aspects of objective for construction scale and to observe the change of function requirements of controversy.

1) The Project's goal

Project's goal is to follow the basic principle of all the activities of the project to achieve the project goals for the guidelines. Project goal simply is the implementation of the project to achieve the desired result, the project can deliver results and/or services. The implementation of the project process is actually a kind of pursuit of goals. Therefore, in a sense, the project goals should be clearly defined, and can be finally realize, so the change of the aim of the project belongs to the functional requirements change.

2) The construction scale

Determine the construction scale of an indispensable part of the client requirements, is a key factor to control the cost problem. Construction scale is specified in the project feasibility study report for all design production capacity, or investment total scale efficiency, reflects the Labor force, means of labor and object of labor productivity elements concentration [13] in the investment projects. Every construction project is a reasonable size of selection problem. Method for determining the construction scale production includes break-even analysis, the average cost method, production capacity balance method and the government or industry regulations [14]. In project construction scale divided into, for example, for general public buildings according to their characteristics can be divided into large, medium and small buildings.

\section{The contractor can't verify the data and information}

Client requirements needed for the project implementation basic included in the basic data, not all of the data can be through the field survey, some data even experienced contractors were unable to verify. When such data errors, risk shall be borne by the contractor is conform to the principle of fair and just. 


\subsection{Experienced contractors}

"Experienced contractors" this idea is very common in the international engineering, it is determined by the construction industry is the special way to trade, and with the development of the market economy and the construction of the mature is becoming more and more important. In China to international practice, on the basis of gradually adopt the concept of "experienced contractor". Experienced contractor refers to as the main body of the actual conditions of prediction about the future, should have all aspects related to engineering experts, has rich experience in similar project construction and management, its foresee obstacles or conditions should adapt to the experts predict ability [15].

\subsection{Cannot verify the judgment standard data and information}

The contractor according to the developer to provide basic data and material, should organize relevant personnel to the site survey in a timely manner. Site is very important for engineering project management, understand the construction site situation is conducive to the contractor, more conducive to the smooth implementation of the project, and reduce disputes and disputes [16]. Contractor's field does not need to use the special knowledge of geology and geotechnical engineering, but through the field survey, the contractor must be clear whether have found or to foresee the likely probability of adverse conditions [17], and included in the initial contract.

Contractor in verify the developer to provide basic data and information, and not every material has the ability to verify, as some unforeseen special conditions, even experienced the contractor cannot be foreseen in advance, such data is the judgment standard of probability based on past time period. For example, the developer can only collect past weather conditions, not predict the weather in the next few years and the contractor cannot foresee a bad weather suddenly appeared, due to the longer the duration of the project, equipment damage caused by abnormal weather, such as the shutdown losses, the contractor shall have the right to demand compensation to the developer. Very discreet if there are any adverse conditions in the field, such as construction site found that cultural relic, this kind of situation even experienced contractor in check after the relevant contract documents and field survey are still unable to foresee, after these events, the contractor can put forward to compensate the time limit for a project, cost to the developer and proper profit.

There are other conditions not listed, refer to figure 2 data and data definition methods about impossible to verify.

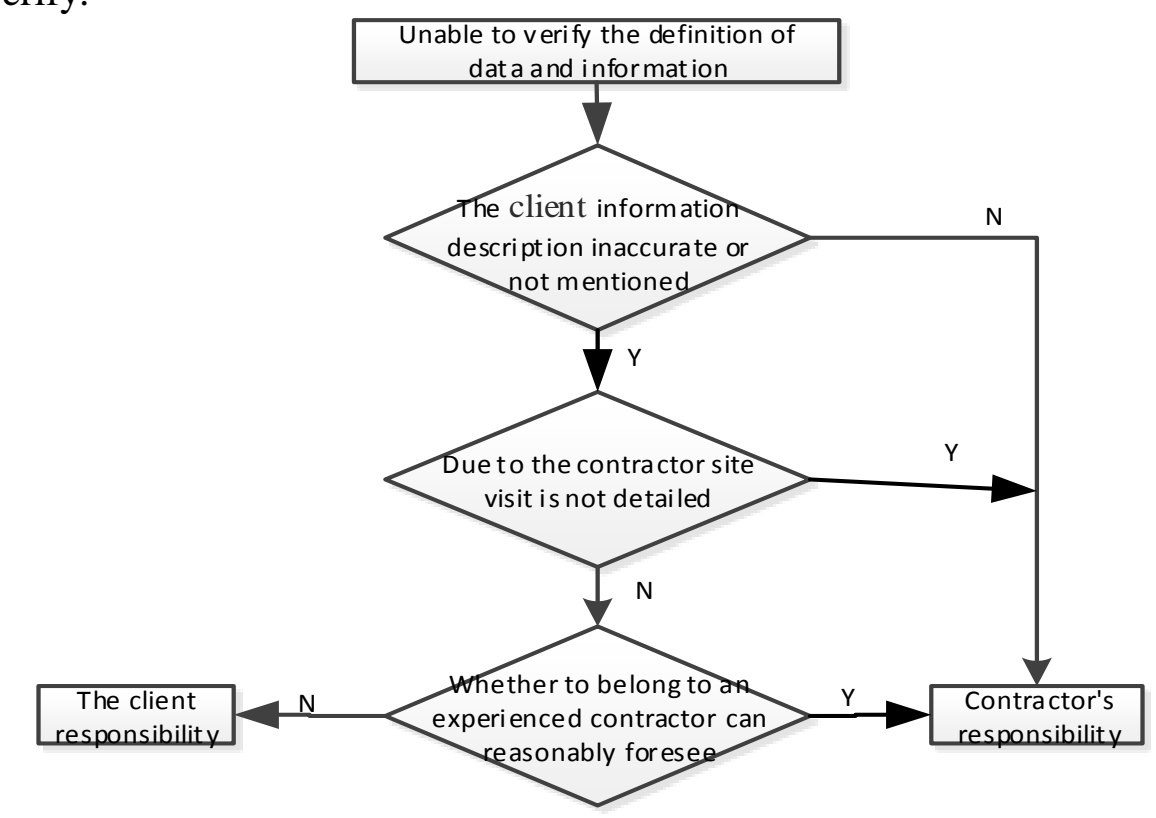

Figure 2 Data and data definition methods about impossible to verify.

Client requirements errors of five kinds of circumstances in addition to the above three conditions, include process arrangement or requirements for engineering and test and inspection standards, including test and inspection standards in the functional requirement of the engineering, and engineering process arrangement or requirements with the surrounding environment is closely related 
to the construction site. Engineering construction technology including earthworks, foundation and foundation engineering, underground waterproof engineering, concrete engineering, steel structure engineering, building, floor and ground engineering, doors and Windows engineering, decoration engineering, and roofing construction. If the construction technology of destroy the surrounding environment, influence the behavior of residents' normal life around, the resulting losses shall be borne by the employer, but the contractor should also be strict with construction personnel specification construction technology in the construction process, avoid to cause unnecessary loss.

\section{Summary}

In terms of a whether the developer errors in the contractor found that losses shall be borne with the developer. Contractor in line with the social morality, the discovery of the error timely notify the developer can, it can also promote the affection between the two sides is conducive to the smooth implementation of the project; If found no errors in the client requirements, the contractor shall not take any risk. For B terms, the situation is more than a clause complex. First of all, the real mistake to client request, the client insist on don't modify, the contractor is not responsible, losses shall be borne by the developer. But this kind of situation is less commonly, in the case of both contracting good communication, client requirements if there is an error can be modified in time, ensure the smooth implementation of the project. Second, except otherwise agreed by the five kinds of situation by the developer to take risks, the loss caused by other conditions are the responsibility of contractor. B terms will bring the part of the client requirements risk transfer to the contractor, are unfair but at the same time pay to the contractor of high interest as compensation. This paper emphatically analyses the risk under the terms of B share the key points, to explain when the contracting parties have disputes, how to determine the developer requires the error caused by the losses shall be borne by the who.

Engineering change is in order to make up for the contracting differences in initial state and the state of nature and set up, implement engineering change to meet the developer of the specific requirements of the construction project, at the same time guarantee the contractor labor income. The establishment of engineering change original intention is to realize the qualified construction project that could satisfy the requirement of the employer, at the same time to ensure that the contractor paid Labor, is in view of the project uncertainty and set the status of the adjustment and compensation space

\section{References}

[1] Hong Ke, Jie Bai. Based on rough set theory of incomplete contract evaluation studies - 07 standard construction bidding documents [J]. Scientific and technological progress and countermeasures, 2012, 18:86-90.

[2] Hart O, Moore J. Foundations of Incomplete Contracts [J]. The Review of Economic Studies, 1999, 66(1): 115-138.

[3] $\mathrm{Na}$ Chen, Qiufeng Qu. The risk sharing model research in DB mode [J]. Construction management modernization. 2009, (12):1-2.

[4] Yuke Liu. The general contract of construction project engineering demonstration text (try out) "composition, structure and outline of clause interpretation (one) [J]. China survey and design, 2011(11): 7-16.

[5] Hao Wang, Huiming Lu. Standard design and construction general contract terms and conditions of the tender documents [J]. Journal of engineering management,2013,(06):77

[6] Chunag Qiu. International engineering contract and pragmatic principle [M].Beijing: China building industry press, 2002. 
[7] Jialiang Zhou, Gie Huang. Underground pipeline measurement methods and quality control [J]. The China science and technology information.2014 (03):53-54.

[8] Wenge Qiu. Underground engineering near the construction mechanics principle and countermeasure research [D]. Southwest Jiaotong University.2003.

[9] Lingwen Wang. Almost complex analysis village heads of control network layout and location, by taking measurements [J]. Gansu science and technology aspect. 2007.36 (05):137-138.

[10] Mengshu Wang, Chengping Zhang. Accident analysis of urban underground engineering construction, and control countermeasures [J]. Journal of construction science and engineering. $2008.25(02): 1-5$.

[11] Keqi Bao. Engineering scale, the time limit for a project and the total cost of construction, based on a large state-owned construction enterprise project cost data of empirical research [D]. Southwestern university of finance and economics. 2012.

[12] Jian Chen, Huipu Zhang. International engineering claims under the FIDIC contract management - Africa some highway project claim the empirical analysis [J]. International economic cooperation.2007 (9):59-62.

[13] Hao Tian. Project evaluation methods and applications [M]. Shanxi people's publishing house, 2005.06.

[14] Tingfeng Zhang. The theory of project construction scale [J]. Small and medium-sized enterprise management and technology, 2010(31):253-254.

[15]Hongwei Liu. FIDIC contract conditions, the contractor claims study [D]. Suzhou university.2006.

[16] Yu wang, Qun tan. Discuss how to avoid in the engineering bidding project claim [J]. Sichuan hydropower, 2011, 30(5):68-70.

[17] Na Li, Qie Shen. Theory of experienced contractors [J]. The construction technology.2007.36 (7):96-98. 